\title{
Thrombocytopenia in pregnancy
}

\author{
Sarah L. Janes \\ Haemophilia Centre and Haemostasis Unit, Royal Free Hospital and School of Medicine, \\ London NW3 2QG, UK
}

\section{Introduction}

Thrombocytopenia is defined as a platelet count of less than $150 \times 10^{9} / 1$. Normal pregnancy is generally thought not to affect the platelet count, ${ }^{1}$ but it has been suggested that the normal range is lower in pregnancy, and that the count falls in the third trimester. ${ }^{2-4}$ This review concentrates on causes of thrombocytopenia with particular reference to pregnancy: most of these involve excessive platelet consumption (Table I).

\section{Failure of platelet production}

Demand for folic acid rises to $300-400 \mu \mathrm{g} /$ day in normal pregnancy, and dietary deficiency may cause thrombocytopenia, particularly where demand is increased by multiple pregnancy, or by an underlying haemolytic state. ${ }^{5}$ Combined iron and folate supplements usually provide $350 \mu \mathrm{g}$ of folate daily.

Aplastic anaemia and paroxysmal nocturnal haemoglobinuria, although rare, do occur in young women, and there is anecdotal evidence for an association of both with pregnancy. ${ }^{6}$ Colvin reviews other coincidental causes, such as congenital thrombocytopenias, and malignancies. ${ }^{6}$

\section{Excessive platelet consumption}

This is observed in idiopathic (auto-immune) thrombocytopenia (ITP), pre-eclampsia/eclampsia, disseminated intravascular coagulopathy (DIC), and thrombotic thrombocytopenia purpura (TTP). Accelerated platelet activation and consumption characterize normal pregnancy, ${ }^{7,8}$ which may partly explain the common finding of mild thrombocytopenia (platelets $100-150 \times 10^{9} / 1$ ), known as

Correspondence: S.L. Janes, M.R.C.P.

Received: 7 November 1991 pregnancy-associated (PAT), gestational asymptomatic or incidental thrombocytopenia. ${ }^{2,9-12}$

\section{Idiopathic thrombocytopenic purpura}

Chronic ITP is a common auto-immune disorder in young women. Platelet-associated IgG (PAIgG) is detected in over $90 \%$ of cases, and circulating anti-platelet antibodies in about $50 \%$. These are not specific for ITP, however, occurring also in pre-eclampsia, PAT, and possibly in normal pregnancy. ${ }^{2,13-15}$ In $95 \%$ of cases the antibody class is IgG, and $90 \%$ of these are $\operatorname{IgG}_{1},{ }^{16}$ which can cross the placenta. The antibodies are often directed against glycoproteins IIb, IIIa or Ib. ${ }^{17}$ ITP may complicate $20 \%$ of pregnancies in women with systemic lupus erythematosus ${ }^{18}$ (reviewed by de Swiet) ${ }^{19}$ and may be the presenting feature in $5-10 \%$ of cases of human immunodeficiency virus (HIV) infection. ${ }^{20}$

Management must address the possibility of fetal involvement. Anti-platelet IgG may cross the placenta and cause thrombocytopenia, which if severe (less than $50 \times 10^{9} / 1$ ) carries a high risk of

Table I Causes of thrombocytopenia in pregnancy

\begin{tabular}{lr}
\hline Reduced production \\
Congenital \\
Precursor deficiency \\
Marrow failure \\
Malignancy \\
Increased consumption \\
Idiopathic (auto-immune) thrombocytopenia \\
Pre-eclampsia/eclampsia \\
Thrombotic thrombocytopenic purpura \\
Disseminated intravascular coagulopathy \\
Drugs including heparin \\
Alloimmune thrombocytopenia \\
\hline $\mathbf{M}$ \\
\hline $\mathbf{M}=$ disease process causes thrombocytopenia in mother; \\
$\mathbf{F}=$ disease process causes thrombocytopenia in fetus.
\end{tabular}


intra-cranial haemorrhage during vaginal delivery. ${ }^{21}$ Thirty to $40 \%$ of infants of women with ITP have platelets of less than $100 \times 10^{9} / 1$, and $5-20 \%$, less than $50 \times 10^{9} / 1 .^{14,22,23}$ (Earlier reports cited a higher incidence of affected infants ${ }^{24,25}$ ). The risk remains similar for subsequent pregnancies. Management therefore depends on whether the fetus is affected, whether ante-natal treatment is effective, and which method of delivery is safer.

Treatment of the mother should aim to prevent bleeding, by maintaining a platelet count of over $20 \times 10^{9} / 1,^{26}$ and up to $50-100 \times 10^{9} / 1$ for delivery. ${ }^{27,28}$ Monitoring the bleeding time (which tends to be disproportionately short for the platelet count in ITP, because the platelets are young and reactive) may help reduce unnecessary therapy. ${ }^{28}$ Corticosteroids $(1 \mathrm{mg} / \mathrm{kg} /$ day, reducing to a maintenance dose as soon as possible) remain first line treatment, but should be used cautiously, because of a risk of precipitating pre-eclampsia, and of adrenal suppression affecting fetal development, ${ }^{26}$ and immuno-suppression should be avoided. ${ }^{6,26,27,29}$ Second trimester splenectomy proved hazardous, and has largely been discontinued. ${ }^{30,31}$

Intravenous IgG (i.v. IgG: $0.4 \mathrm{~g} / \mathrm{kg}$ body weight/ day for 5 days) was first noted to be effective in childhood ITP in $1981 .{ }^{32}$ Treatment is followed by a consistent rise in the platelet count in almost all patients, which lasts for 2-4 weeks, so delivery can usually be covered by a course of i.v. IgG given at about 38 weeks. $^{6}$ The main drawback is cost. Improved supportive care, i.v. IgG and platelet transfusions for severe bleeding and emergency surgery have reduced maternal risk considerably. ${ }^{26}$

The fetal platelet count is not predicted by the maternal platelet count, PAIgG, nor presence of circulating antibodies, ${ }^{11,15,33,34}$ and discordant twin pregnancies may occur; ${ }^{35}$ but a history of ITP indicates a significant risk of fetal thrombocytopenia. ${ }^{9,14,15}$ That previous splenectomy has particular significance ${ }^{30}$ is now doubtful. ${ }^{23,33,34}$ The absence of circulating antibodies may predict a very low risk of fetal thrombocytopenia, ${ }^{14,36}$ but there are frequent exceptions, and consistent results are difficult to obtain. ${ }^{9}$

Attempts to treat the affected fetus have been disappointing. Maternal corticosteroids do not consistently reduce the incidence of fetal thrombocytopenia. ${ }^{37,38}$ Thrombocytopenic infants have been born to mothers whose counts have responded to i.v. IgG pre-delivery. ${ }^{39,40}$ Placental transfer of IgG requires an intact $\mathrm{Fc}$ portion, and may take 3 weeks to equilibrate. ${ }^{41}$

Therefore, at present, there is no effective antenatal treatment, although some advocate steroids. ${ }^{42}$ The fetal platelet count can be measured directly by fetal scalp blood sampling early in labour, ${ }^{24,33,43}$ or by percutaneous umbilical blood sampling (PUBS). ${ }^{11,22,44}$ The former may be technically impossible, or give falsely low counts. ${ }^{23,45,46}$ PUBS at term appears safe in experienced hands: ${ }^{11,22,44}$ current treatment options do not justify the increased risks earlier in pregnancy. If the fetal platelet count is below $50 \times 10^{9} / 1$, delivery should be by Caesarean section, ${ }^{11,25-28,43}$ and emergency facilities for this must be available. ${ }^{44}$ The infant's platelet count often falls further during the first week post-natally, requiring monitoring, and possibly treatment. ${ }^{47}$

\section{Pregnancy-associated thrombocytopenia}

Women with asymptomatic thrombocytopenia in pregnancy and platelet counts rapidly returning to normal post-delivery probably have PAT, with a low incidence of fetal complications. PAT is common: in recent series the incidence was $0.4-8.3 \%$, or more. ${ }^{2,10,12,14,15}$ The platelet count is usually $100-150 \times 10^{9} / 1$, although it may be as low as $50 \times 10^{9} / 1$, and falls slowly. ${ }^{2}$ The fetus is not at risk: none of 330 infants had platelets of less than $50 \times 10^{9} / 1$. The problem is to distinguish PAT from chronic ITP, in order to avoid unnecessary intervention. Laboratory tests are not conclusive, so eliciting a past history of ITP is very important.

Therefore, for all women with a history of ITP predating pregnancy, ${ }^{9,14,15}$ whatever their currene count, and probably for women with plateletso below an arbitary number, perhaps $75 \times 10^{9} / 1$, who are more likely to have ITP, ${ }^{2,14}$ corticosteroids and/or i.v. IgG should be used to achieve haemostasis in the mother. A fetal platelet count obtained immediately pre-delivery, and obstetric considerations, should determine the method of delivery.

If there is no history of ITP, and particularly if the maternal count exceeds $100 \times 10^{9} / 1$, there is little risk of a thrombocytopenic infant, and invasive sampling is not necessary. ${ }^{9,11,14}$

\section{Alloimmune thrombocytopenia}

This is discussed to compare and contrast it with ITP. About $2 \%$ of women are negative for common platelet antigens, such as $\mathrm{PlA}_{1}(\mathrm{Zwa})$, and may develop antibodies against the paternally derived antigen on fetal platelets (analogous to Rhesus haemolytic anaemia). ${ }^{48}$ Unlike ITP, the woman is unaffected, unless she develops thrombocytopenia and 'post-transfusion purpura' following blood transfusion, ${ }^{49}$ but her fetus may be severely thrombocytopenic. Delivery should be by Caesarean section in known caes, ${ }^{26}$ but management is complicated by increasing recognition of antenatal intracranial bleeds, ${ }^{50-52}$ and because the first child is affected in $50 \%$ of cases, ${ }^{53}$ with severity tending to increase with subsequent pregnancies. PUBS 
and in utero platelet transfusions, with $\mathbf{P l A}_{1}$ negative platelets, have been advocated, ${ }^{54,55}$ as has maternal i.v. IgG, ${ }^{56}$ and antenatal screening for $\mathrm{PlA}_{1}$, to detect women at risk..$^{53} \mathrm{~A}$ woman with a previous affected pregnancy should be managed at a major centre. Management of the thrombocytopenic neonate is discussed by MuellerEckhardt. ${ }^{48}$

\section{Pre-eclampsia and pregnancy-induced hypertension}

Thrombocytopenia occurs in $17-50 \%$ of preeclamptic women, ${ }^{13,57-60}$ and may precede the development of hypertension, or occur without it. ${ }^{61}$ There is increasing evidence of the pivotal role of platelets in the development of pre-eclampsia and intra-uterine growth retardation, ${ }^{62,63}$ and of the effectiveness of anti-platelet agents in preventing these ${ }^{64}$ Platelet lifespan is reduced, ${ }^{65}$ and activation increased as shown by raised beta-thromboglobulin levels.$^{66}$ Changes in platelet calcium flux may be detectable as early as the first trimester in women who later develop pre-eclampsia. ${ }^{62}$ Overt DIC is uncommon, and standard coagulation assays are usually normal, but platelet dysfunction ${ }^{59,67-69}$ may be reflected by a prolonged bleeding time. ${ }^{54,69,70}$

The treatment for progressive pre-eclampsia, including thrombocytopenia, remains delivery, and the thrombocytopenia then rapidly resolves. ${ }^{60}$ The ongoing CLASP trial should determine whether low-dose aspirin can prevent pre-eclampsia, which would represent a major advance in managing this problem.

The HELLP syndrome (haemolysis, elevated liver function tests, low platelet counts) is a serious complication of pre-eclampsia, ${ }^{71}$ affecting about $8.5 \%$ of severe pre-eclamptics, ${ }^{58}$ and perinatal mortality may approach $50 \%$. It is vital to recognize the syndrome, even in the absence of marked hypertension, as recovery may necessitate immediate delivery, despite fetal immaturity. ${ }^{71,72}$ Following delivery, the illness regresses rapidly. Close monitoring of a stable patient may allow fetal maturation. ${ }^{73}$

Infants of pre-eclamptic women are unlikely to be thrombocytopenic, except when they have other complications of prematurity. ${ }^{74,75}$

\section{Thrombotic thrombocytopenic purpura - haemolytic uraemic syndrome}

TTP is rare, and the cause is unknown. The pentad of features (fever, neurological disturbances, renal impairment, thrombocytopenia and microangiopathic haemolytic anaemia) is due to intravascular platelet clumping. The closely related haemolytic uraemic syndrome usually presents postnatally with acute renal failure. ${ }^{76}$ TTP has been linked to pregnancy, ${ }^{76}$ and oral contraceptive medication, ${ }^{6}$ and there may also be an association with HIV .77

Prior to 1980 the disease was usually fatal, ${ }^{78}$ and prompt delivery did not affect the outcome, ${ }^{76}$ but two recent series with a total of 210 patients report successful treatment of $71 \%$ and $91 \%$ of cases respectively. ${ }^{77,79}$ The most effective treatment was plasma exchange with fresh frozen plasma (FFP) replacement, \pm high dose prednisone. Nine pregnant women presented with TTP in the third trimester; they all survived and delivered unaffected babies, and five subsequently had normal pregnancies. ${ }^{77}$ A high molecular weight fraction of FFP, requiring smaller infusion volumes, may also be useful. ${ }^{80}$ Platelet transfusions are contra-indicated.

\section{Disseminated intravascular coagulopathy}

Obstetric problems are important causes of DIC, which may complicate placental abruption, preeclampsia, intra-uterine death or infection, uterine rupture and amniotic fluid embolism. Management is that of the underlying cause, with supportive therapy, including platelet and factor replacement as required. Heparin is advocated in cases where the vascular tree is intact, such as amniotic fluid embolism and the chronic DIC accompanying retention of a dead fetus.$^{81}$ Heparin is also important in the prevention of gangrene in the rare and serious post-partum complication of Gram-negative septicaemia and DIC, purpura fulminans. ${ }^{82}$

DIC and thrombocytopenia are also features of acute fatty liver of pregnancy. The maternal and fetal mortality (both around $80 \%$ ) in this rare syndrome appear reduced by prompt delivery, and so recognition of impending hepatic and renal failure in the third trimester is vital. ${ }^{26,83}$

\section{Heparin}

In $0.6-9 \%$ of patients, heparin induces antiplatelet IgG, which can cause thrombocytopenia and thrombosis, often arterial, due to complementmediated platelet activation. ${ }^{84,85}$ This action is heparin-dependent, and as heparin does not cross the placenta, the fetus is not affected. It occurs 7-14 days after the initiation of heparin therapy, and can complicate even low-dose therapy, with significant mortality and risk of amputation. If heparin is unavoidable, heparin from a different source may be safer. ${ }^{86}$

Thrombocytopenia during pregnancy has also been reported as complicating mild type IIb von Willebrand's disease,$^{87,88}$ and chorioangioma of the placenta, ${ }^{89}$ and as spurious due to EDTA-induced platelet clumping. ${ }^{90}$ 


\section{Conclusion}

Thrombocytopenia is a common finding in pregnancy, and careful diagnosis is important to distin-

\section{References}

1. Fenton, V., Saunders, K. \& Cavill, I. The platelet count in pregnancy. J Clin Path 1977, 30: 68-69.

2. Matthews, J.H., Benjamin, S., Gill, D.S. \& Smith, N.A. Pregnancy associated thrombocytopenia: definition, incidence and natural history. Acta Haematol Basel 1990, 84: 24-29.

3. Fay, R.A., Hughes, C. \& Farron, N.T. Platelets in pregnancy: hyperdestruction in pregnancy. Obstet Gynecol 1983, 61: 238-240.

4. Stirling, Y., Woolf, L., North, W.R.S., Seghatchian, M.J. \& Meade, T.W. Haemostasis in normal pregnancy. Thromb Haemostas 1984, 52: 176-182.

5. Chanarin, I., Rothman, D., Ward, A. \& Perry, J. Folate status and requirement in pregnancy. $B r M e d J$ 1968, ii: 390-394.

6. Colvin, B.T. Thrombocytopenia. Clin Haematol 1985, 14: 661-681.

7. Douglas, J.T., Shah, M., Lowe, G.D.O., Belch, J.J.F., Forbes, C.D. \& Prentice, C.R.M. Plasma fibrinopeptide A and beta-thromboglobulin in preeclampsia and pregnancyinduced hypertension. Thromb Haemostas 1982, 47: 54-55.

8. Fitzgerald, D.J., Mayo, G., Cateela, F., Entman, S.S. \& Fitzgerald, G.A. Increased thromboxane synthesis in normal pregnancy is mainly derived from platelets. Am J Obstet Gynecol 1987, 157: 325-330.

9. Aster, R.H. 'Gestational' thrombocytopenia. A plea for conservative management (editorial). N Engl J Med 1990, 323: 264-266.

10. How, H.Y., Bergmann, F., Koshy, M., Chediak, J., Presperin, C. \& Gall, S.A. Quantitative and qualitative platelet abnormalities during pregnancy. Am J Obstet Gynecol 1991, 64: 92-98.

11. Sacher, R.A. ITP in pregnancy and the newborn: introduction. Blut 1989, 59: 124-127.

12. Burrows, R.F. \& Kelton, J.G. Incidentally detected thrombocytopenia in healthy mothers and their infants. $N$ Engl $J$ Med 1988, 319: 142-145.

13. Gibson, B., Hunter, D., Neame, P.B. \& Kelton, J.G. Thrombocytopenia in preeclampsia and eclampsia. Sem Thromb Haemostas 1982, 8: 234-247.

14. Samuels, P., Bussel, J.B., Braitman, L.E. et al. Estimation of the risk of thrombocytopenia in the offspring of pregnant women with presumed ITP. $N$ Engl J Med 1990, 323: 229-235.

15. Hart, D., Dunetz, C., Nardi, M., Porges, R.F., Weiss, A. \& Karpatkin, M. An epidemic of maternal thrombocytopenia associated with elevated anti-platelet antibody. Am J Obstet Gynecol 1986, 154: 878-883.

16. Burstein, S.A., McMillan, R.M. \& Karker, L.A. Quantitative platelet disorders. In: Bloom, A.L. \& Thomas, D.P. (eds) Haemostasis and Thrombosis, 2nd ed. Churchill Livingstone, Edinburgh, 1987, pp. 333-364.

17. Tani, P., Berchtold, P. \& McMillan, R. Autoantibodies in chronic ITP. Blut 1989, 59: 44-64.

18. Lockshin, M.D., Reinitz, E., Druzin, M.L., Murrman, M. \& Estes, D. Lupus pregnancy. Case control study demonstrating absence of lupus exacerbation during or after pregnancy. Am J Med 1984, 77: 893-898.

19. de Swiet, M. Systemic lupus erythematosus and other connective tissue diseases. In: de Swiet, M. (ed.) Medical Disorders in Obstetric Practice, 2nd ed. Blackwell Scientific, Oxford, 1989, pp. 408-425. guish serious causes from benign PAT, and to manage the mother and fetus appropriately.

20. Pottage, J.C., Benson, C.A., Spear, J.B., Landay, A.L. \& Kessler, H.A. Treatment of human immunodeficiency virusrelated thrombocytopenia with zidovudine. JAMA 1988, 260: $3045-3048$.

21. Scott, J.R., Cruikshank, D.P., Kochenow, N.K., Pitkin, R.M. \& Warenski, J.C. Fetal platelet counts in the obstetric management of ITP. Am J Obstet Gynecol 1980, 136: 495-499.

22. Kaplan, C., Daffos, F., Forestier, F. et al. Fetal platelet counts in thrombocytopenic pregnancy. Lancet 1990, 336: 979-982.

23. Burrows, R.F. \& Kelton, J.G. Low risks in pregnancies associated with ITP. Am J Obstet Gynecol 1990, 163: 1147-1150.

24. Beck, R. Perinatal and neonatal aspects of maternal ITP. Am J Perinatol 1984, 1: 251-258.

25. Kelton, J.G. Management of the pregnant patient with idiopathic thrombocytopenic purpura. Ann Intern Med 1983 99: 796-800.

26. Letsky, E.A. Coagulation Problems during Pregnancy. Churchill Livingstone, Edinburgh, 1985, pp. 101-105.

27. Hathaway, W.E. \& Bonnar, J. Haemostatic Disorders of the Pregnant Woman and Newborn Infant. John Wiley and Sons, Chichester, 1987, pp. 84-88.

28. Ballem, P.J., Buskard, N., Wittmann, B.K., Wilson, R.D.尺 Effer, S. \& Farquharson, D. ITP in pregnancy: use of the bleeding time as an indicator for treatment. Blut 1989, 59: $132-135$

29. Hegde, U.M. Immune thrombocytopenia in pregnancy and the newborn (editorial). Br J Obstet Gynecol 1985, 92: 657-659.

30. Carloss, H.W., McMillan, R. \& Crosby, W.H. Management of pregnancy in women with ITP. JAMA 1980, 244: 2756-2758.

31. Paul, J.D., Pranckun, P.P. \& Grosh, J.L. Splenectomy for ITP in pregnancy. Obstet Gynecol 1966, 28: 336-338.

32. Imbach, P., Barandum, S. \& d'Apuzzo, V. High dose intravenous gammaglobulin for ITP in childhood. Lancet 1981 , i: $1128-1131$

33. Scott, J.R., Rote, N.S. \& Cruikshank, D.P. Antiplatelet antibodies and platelet counts in pregnancies complicated by autoimmune thrombocytopenic purpura. Am $\mathrm{J}$ Obstet Gynecol 1983, 145: 932-929.

34. Moutet, A., Fromont, P., Farcet, J.P. et al. Pregnancy in women with ITP. Arch Int Med 1990, 150: 2141-2145.

35. Moise, K.J. \& Cotton, D.B. Discordant fetal platelet counts in a twin gestation complicated by ITP. Am J Obstet Gynecol 1987, 156: $1141-1142$.

36. Cines, D.B., Dusak, B., Tomaski, A., Mennuti, M. \& Schreiber, A.D. ITP and pregnancy. $N$ Engl J Med 1982, 306: 826-831.

37. Donner, M., Aronsson, S., Holmberg, L. \& Olofsson, P. Corticosteroid treatment of maternal ITP and the risk of neonatal thrombocytopenia. Acta Paediatr Scand 1987, 76: 369-371.

38. Christiaens, G.C., Nieuwenhuis, H.K., von dem Borne, A.E., Ouwehand, W.H., Helmerhorst, F.M., van Dalen, C.M. \& Van der Tweel, I. ITP in pregnancy: a randomized trial on the effect of antenatal low dose corticosteroids on neonata platelet count. Br J Obstet Gynecol 1990, 97: 893-898. 
39. Davies, S.V., Murray, J.A., Gee, H. \& Giles, H.M. Transplacental effect of high-dose immunoglobulin in ITP. Lancet 1986, i: $1098-1099$.

40. Pappas, C. Placental transfer of immunoglobulins in ITP. Lancet 1986, i: 389.

41. Newland, A.C. \& Patterson, K.G. Intravenous IgG for autoimmune thrombocytopenia in pregnancy. $N$ Engl $\mathrm{J}$ Med 1984, 310: 261-266.

42. Karpatkin, M.I., Porges, R.F. \& Karpatkin, S. Platelet counts in infants of women with autoimmune thrombocytopenia. $N$ Engl J Med 1981, 305: 936-939.

43. Dan, U., Barkai, G., David, B., Goldenberg, M., Kukkia, E. \& Mashiach, S. Management of labor in patients with idiopathic thrombocytopenic purpura. Gynecol Obstet Invest 1989, 27: 193-196.

44. Moise, K.J., Carpenter, R.J., Cotton, D.B., Wasserstrum, N., Kirshon, B. \& Cano, L. Percutaneous umbilical cord blood sampling in the evaluation of fetal platelet counts in pregnant patients with autoimmune thrombocytopenic purpura. Obstet Gynecol 1988, 72: 346-350.

45. Wahbeh, C.J., Eden, R.D., Killam, A.P. \& Gall, S.A Pregnancy and ITP. Am J Obstet Gynecol 1984, 149: 238-240.

46. Christiaens, G.C. \& Helmerhorst, F.M. Validity of intrapartum diagnosis of fetal thrombocytopenia. Am J Obstet Gynecol 1987, 157: 864-865.

47. Blanchette, V., Andrew, M., Perlman, M., Ling, E. \& Ballin, A. Neonatal autoimmune thrombocytopenia: role of highdose intravenous immunoglobulin $G$ therapy. Blut 1989, 59: 139-144.

48. Mueller-Eckhardt, C., Kiefel, V., Brubert, A. et al. 348 cases of suspected neonatal alloimmune thrombocytopenia. Lancet 1989 i: $363-366$

49. Waters, A.H. Post-transfusion purpura. Blood Rev 1989, 3: 83-87.

50. Morales, W.J. \& Stroup, M. Intracranial haemorrhage in utero due to isoimmune neonatal thrombocytopenia. Obstet Gynecol 1985, 65: 20S-21S.

51. Herman, J.H., Jumbelic, M.I., Ancona, R.J. \& Kickler, T.S. In utero cerebral haemorrhage in alloimmune thrombocytopenia. Am J Pediatr Hematol Oncol 1986, 8: 312-317.

52. Burrows, R.F., Caco, C.C. \& Kelton, J.G. Neonatal alloimmune thrombocytopenia: spontaneous in utero intracranial haemorrhage. Am J Hematol 1988, 28: 98-102.

53. Editorial. Management of alloimmune neonatal thrombocytopenia. Lancet 1989 , i: 137-138.

54. Nicolini, U., Rodeck, C.H., Kochenour, N.K. et al. In utero platelet transfusion for alloimmune thrombocytopenia. Lancet 1988, ii: 506.

55. Kaplan, C., Daffos, F., Forestier, F. et al. Management of alloimmune thrombocytopenia: antenatal diagnosis and in utero transfusion of maternal platelets. Blood 1988, 72 . $340-343$.

56. Bussel, J.B., Berkowitz, R.L., McFarland, J.G., Lynch, L. \& Chitkara, U. Antenatal treatment of neonatal alloimmune thrombocytopenia. $N$ Engl J Med 1988, 319: 1374-1378.

57. Giles, C. \& Inglis, T.C.M. Thrombocytopenia and macrothrombocytosis in gestational hypertension. $\mathrm{Br} \mathrm{J}$ Obstet Gynecol 1981, 88: 1115-1119.

58. Sibai, B.M., Spinnato, J.A., Watson, D.L., Hill, G.A. \& Anderson, G.D. Pregnancy outcome in 303 cases with severe preeclampsia. Obstet Gynecol 1984, 64: 319-325.

59. Burrows, R.F., Hunter, D.J.S., Andrews, M. \& Kelton, J.G. A prospective study investigating the mechanism of thrombocytopenia in preeclampsia. Obstet Gynecol 1990, 70: 334-338.

60. Katz, V.L., Thorp, J.M., Rozas, L. \& Bowes, W.A. The natural history of thrombocytopenia associated with preeclampsia. Am J Obstet Gynecol 1990, 163: 1142-1143.

61. Redman, C.W.G., Bonnar, J. \& Beilin, L. Early platelet consumption in pre-eclampsia. $\mathrm{Br}$ Med J 1978, i: 467-470.
62. Zemel, M.B., Zemel, P.C, Berry, S. et al. Altered platelet calcium metabolism as an early predictor of increased peripheral vascular resistance and pre-eclampsia in urban black women. $N$ Engl J Med 1990, 323: 434-437.

63. Redman, C.W.G. Platelets and the beginnings of preeclampsia (editorial). $N$ Engl J Med 1990, 323: 478-480.

64. Wallenberg, H.C.S., Dekker, G.A., Makowitz, V.W. \& Rotsmans, $R$. Low dose aspirin prevents pregnancy-induced hypertension and pre-eclampsia in angiotensin II sensitive primiparae. Lancet 1986, ii: 1-3.

65. Rakoczi, T., Tallian, F., Bagdany, S. \& Gati, I. Platelet lifespan in normal pregnancy and pre-eclampsia as determined by a nonradioisotope technique. Thromb Res 1979, 15: $553-556$.

66. Douglas, J.T., Shah, M., Lowe, G.D.O., Belch, J.J.F., Forbes, C.D. \& Prentice, C.R.M. Plasma fibrinopeptide A and beta-thromboglobulin in pre-eclampsia and pregnancy induced hypertension. Thromb Haemostas 1982, 47: 54-55.

67. Whigham, K.A.E, Howie, P.W., Drummond, A.H. \& Prentice, C.R.M. Abnormal platelet function in pre-eclampsia. $\mathrm{Br}$ J Obstet Gynaecol 1978, 85: 28-32.

68. Goodlin, R.C. \& Davies, R.B. Diagnosis and treatment of pregnancy induced platelet dysfunction. Clin Exp Hypertens $B$ 1983, 2: 15-19.

69. Kelton, J.G., Hunter, D.J. \& Neame, B. A platelet function defect in preeclampsia. Obstet Gynecol 1985, 65: 107-109.

70. Ramanathan, J., Sibai, B.M., Vu, T. \& Chauhan, D. Correlation between bleeding times and platelet counts in women with pre-eclampsia undergoing caesarean section. Anaesthesiology 1989, 71: 188-191.

71. Weinstein, L. Syndrome of hemolysis, elevated liver enzymes, and low platelet count: a severe consequence of hypertension in pregnancy. Am J Obstet Gynecol 1982, 142: 159-167.

72. Weinstein, L. Preeclampsia/eclampsia with hemolysis, elevated liver enzymes, and thrombocytopenia. Obstet Gynecol 1985, 66: 657-660.

73. MacKenna, J., Dover, N.L. \& Brame, R.G. Pre-eclampsia associated with hemolysis, elevated liver enzymes and low platelets - an obstetric emergency? Obstet Gynecol 1983, 62, $751-754$.

74. Pritchard, J.A., Cunningham, F.G., Pritchard, S.A. \& Mason, R.A. How often does maternal preeclampsiaeclampsia incite thrombocytopenia in the fetus? Obstet Gynecol 1987, 69: 292-295.

75. Burrows, R.F. \& Andrew, M. Neonatal thrombocytopenia in the hypertensive disorders of pregnancy. Obstet Gynecol 1990, 76: 234-248.

76. Boulton, F.E. \& Letsky, E. Obstetric haemorrhage. Clin Haematol 1985, 14: 703-718.

77. Bell, W.R., Braine, H.G., Ness, P.M. \& Kickler, T.S. Improved survival in TTP-HUS. $N$ Engl $J$ Med 1991, 325: 398-403.

78. Moake, J.L. TTP - Desperation, empiricism, progress (editorial). N Engl J Med 1991, 325: 426-428.

79. Rock, G.A., Shumak, K.H., Buskard, N.A. et al. Comparison of plasma exchange with plasma infusion in the treatment of TTP. $N$ Engl J Med 1991, 325: 393-397.

80. Koyama, T., Suehiro, A., Kakishita, E. et al. Efficacy of the high molecular weight fraction of plasma for the maintenance of pregnancy associated with TTP. Am J Haemat 1990, 35: 179-183.

81. Hathaway, W.E. \& Bonnar, J. Haemostatic Disorders of the Pregnant Woman and Newborn Infant. John Wiley and Sons, Chichester, 1987, pp. 90-98.

82. Letsky, E. Coagulation defects. In: de Swiet, M. (ed.) Medical Problems in Obstetric Practice, 2nd ed. Blackwell Scientific, Oxford, 1989, pp. 130-131.

83. Burroughs, A.K., Seong, G., Dojcinoov, D.M., Scheuer, P.J. \& Sherlock, S.V.P. Idiopathic acute fatty liver of pregnancy in 12 patients. $Q J$ Med 1982, 51: 481-497. 
84. Cines, D.B., Kaywin, P., Bina, M., Tomaski, A. \& Schreiber, A.D. Heparin associated thrombocytopenia. $N$ Engl $J$ Med 1980, 303: 788-795.

85. Calhoun, B.C. \& Hesser, J.W. Heparin-associated antibody with pregnancy: discussion of two cases. Am J Obstet Gynecol 1987, 156: 964-966.

86. Meytes, D., Ayalon, H., Virag, I., Weisbort, Y. \& Zakut. H. Heparin induced thrombocytopenia and recurrent thrombosis in pregnancy. A case report. J Reprod Med 1986, 31: 993-996.

87. Rick, M.E., Williams, S.B., Sacher, R.A. \& McKeown, L.P. Thrombocytopenia associated with pregnancy in a patient with type IIB von Willebrand's disease. Blood 1987, 69: 786-789.
88. Giles, A.R., Hoogendoorn, H. \& Benford, K. Type IIB von Willebrand's disease presenting as thrombocytopenia during pregnancy. Br J Haematol 1987, 67: 349-353.

89. Limaye, N.S. \& Tchabo, J.G. Asymptomatic thrombocytopenia associated with chorioangioma of placenta. Am J Obstet Gynecol 1989, 161: 76-77.

90. Solanki, D.L. \& Blackburn, B.C. Spurious thrombocytopenia during pregnancy. Obstet Gynecol 1985, 65: 14S-17S. 